\title{
Analysis of Passenger Transportation Demand: Case Study of the Customs House, the Thai-Laos Friendship Bridge, Nong Khai Province
}

\author{
Sakkarin Nonthapot, Thanet Wattanakul* \\ Khon Kaen University, Thailand \\ *thanetwat@hotmail.com
}

\begin{abstract}
This study analyses the factors influencing passenger transportation demand at the Thai-Laos Friendship Bridge in Nong Khai Province, Thailand. Secondary data was collected from July 2007 to June 2010. The passenger transportation demand model estimation via a unit root test prior to the ordinary least square (OLS) technique found that the passenger number has a long-term, positive equilibrium relationship with the price. On the other hand, gross domestic product (GDP) and the frequency of services provided, have a negative relationship with the exchange rate. The empirical results of a short term analysis based on the error correction mechanism (ECM) estimation revealed that the adjustment speed that affects the number of passengers deviates from the equilibrium point to the long-term equilibrium point by 46.3 percent in each time period. Proposed policy recommendations are as follows: entrepreneurs should increase the frequency and number of services; wider variety of vehicles should be provided; each vehicle should run at full capacity; overall improvement in speed, safety and efficiency of the services is also necessary.
\end{abstract}

Keywords: Passenger Transportation Demand and the Thai-Laos Friendship Bridge

\section{Introduction}

Thailand and the Laos PDR have a very long border of 1,810 kilometers which has been involved with international economic transactions in terms of trade, investment, tourism and passenger transportation over a long period. There are 36 custom check points allowing passenger transportation between the two countries by international bus, train, car, or private hire van. The trend of passenger transportation has recently increased because of the rise of tourists and investors as well as the supporting promotion policy of both countries particularly for the passenger transportation business. The growth of this business can be attributed to the capacity of Nong Khai province with respect to tourist attractions and destinations, food, culture and the natural environment. Therefore, it is very interesting to examine and estimate the passenger transportation demand model in order to investigate the impact of the variables that determine the model. This study also proposes policies that could enhance the effectiveness of entrepreneurs' strategies. Moreover, the results of this study can be used as guidelines for both entrepreneurs and related government organizations.

Objectives and Scope of the Study: This study aims to explore the impact of factors influencing passenger transportation demand via estimating the passenger transportation demand model. The appropriate combination estimation techniques are used. The study period was between July 2007and June 2010 and monthly data was used to estimate the model.

Conceptual Framework: The demand for passenger transportation is used to develop the conceptual framework of this study. It can be explained as follows:

Figure 1: Conceptual Framework of the Study

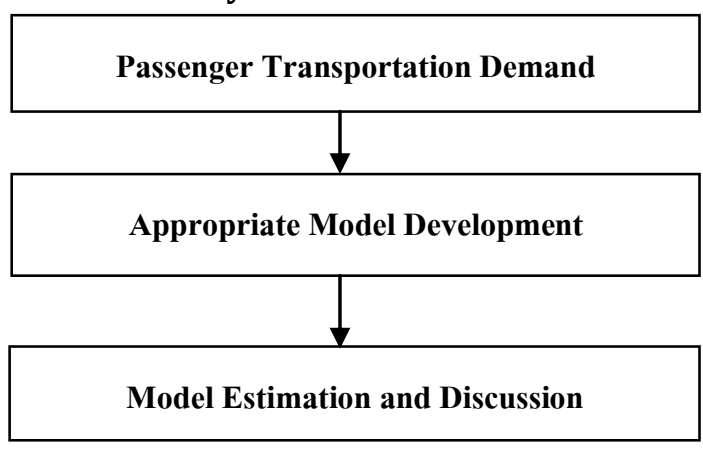


It is necessary to review the passenger transportation demand prior to developing an appropriate model to examine the determinants of passenger transportation. The relationship of determinant variables and passenger transportation demand is explored. To accomplish the study, the discussions and policy implications and recommendations are proposed based on the estimation results.

\section{Literature Review}

This study had been conducted to examine the impact of factors affect the international passenger transportation demand between Thailand and Laos. Therefore, the literature review is the important to be used to construct an appropriate econometric modeling in the next section. Poore (1993) conducted a study to test hypothesis and forecast the future demand of air transportation and the impact of aviation regulations on revenue growth for the major aircraft manufacturers. Matthews (1995) developed the measurement and predicted the passenger flow of various airports in the United Kingdom. It is found that regular air transportation demand can be attributed to the economic factors. The forecasting of passenger flow is essentially related to the long-term planning and infrastructure development level. Yamaguchi et al. (2001) analyzed the economic impact of deregulation of domestic aviation market growth for Japan. It can be concluded that both deregulation and airport capacity extension has significant effect on the growth of market benefit. However, the deregulation criteria need to be the accelerator of passenger demand growth. Hsu and Chao (2005) investigated the relationship between passenger service performance and the terminal size and revenue by constructing the maximum concession revenue model. From the above, it can be noted that most of the recent major studies related to the international passenger transportation demand had been conducted for the other regions and particularly for air transportation. There are only a few studies on Mekong sub-region countries particularly for Thailand and Laos. Moreover, these studies aimed to investigate the elasticity of international passenger transportation demand and forecast the number of passengers regarding to different circumstances. Then, this study is an additional specific research for the Mekong sub-region countries.

\section{Methodology}

This study is based on quantitative analysis by developing an appropriate model to investigate the factors and impact of these factors on passenger transportation demand between Thailand and Laos. The ordinary least square (OLS) is used to estimate the model. Basic econometric problems are also explored and solved to obtain accurate and reliable empirical results as much as possible. The data used to construct model is time series data. The model of study can be described as follows.

Data and Modeling: The data used to develop in this study has been mainly obtained from the Bank of Thailand data base, the annual report of the entrepreneurs, the interview and International Financial Statistics from the IMF. The sample and data covered only the two countries in the Mekong Sub-region according to the objectives of the study. Moreover, the data is both time series and non-time series data. Therefore, it can be affirmed that the data used to construct and estimate the econometric model is suitable. The following linear model was constructed based on the general passenger transportation demand. The variables were developed to suit the passenger transportation between Thailand and Laos.

$$
Q a=f(P a, P b, G D P, E X, H O, T R)
$$

\section{Where:}

Qa is the total number of passengers who use the service provided (people/month)

$\mathbf{P a}$ is the fee paid by customers who use international bus service to travel from Nong Khai to Vientiane deflated by public transportation price (2007 base year, baht/person)

$\mathbf{P b}$ is the fee paid by customers who use the regular bus service to travel from Nong Khai to Vientiane deflated by public transportation price (2007 base year, baht/person)

GDP is the gross domestic product of Thailand (as 1998 constant price, million baht)

EX is the exchange rate (Baht/Kip)

HO is the number of holidays in each month consisting of weekends and special occasion holidays

TR is the frequency of service obtained from the service schedule

From equation (1) above, it can be stated that all the independent variables determine and influence the passenger transportation demand that is represented by total number of passenger who use the service provided (Qa). Additionally, the price of substitute goods is combined in the equation (1) that is expressed by $\mathrm{Pb}$ that is consistent with general demand theory. 
According to equation (1), the linear function can be written in the linear econometric modeling form as follows:

$$
Q a=\beta_{0}+\beta_{1} P a+\beta_{2} P b+\beta_{3} G D P+\beta_{4} E X+\beta_{5} H O+\beta_{6} T R+e_{t} \ldots \ldots \ldots \ldots \ldots . . . . .(2) W h e r e:
$$

$\beta_{0}$ is the constant term

$\beta_{1}-\beta_{6}$ is the coefficient of each independent variable

$\varepsilon_{\mathrm{t}}$ is the error term

Variables Selection: The variables used to estimate co-integration and ECM models almost are time series except some variables such as the number of holidays in each month consisting of weekends and special occasion holidays and the frequency of service obtained from the service schedule. These variables determine the total number of passengers who use the service provided (people/month) that used as proxy variable of passenger transportation demand. Besides that, GDP is the gross domestic product of Thailand (as 1998 constant price, million baht) used to be proxy variable of income which is the direct determinant of passenger transportation demand. However, some variables are not the direct determinant of passenger transportation demand e.g. the fee paid by customers who use international bus service to travel from Nong Khai to Vientiane deflated by public transportation price and the exchange rate (Baht/Kip). These variables obtained and included in the model based on the review literature and the transportation demand theory.

Research Hypotheses: The research hypotheses of this study can be explained as follows. All the research hypotheses are based on the transportation demand theory and other relevant theories.

- $\quad \mathrm{Pa}$ is the fee paid by customers who use international bus service to travel from Nong Khai to Vientiane deflated by public transportation price (2007 base year, baht/person) has significantly negative relationship with the total number of passengers who use the service provided (people/month)

- $\quad \mathrm{Pb}$ is the fee paid by customers who use the regular bus service to travel from Nong Khai to Vientiane deflated by public transportation price (2007 base year, baht/person) has significantly negative relationship with the total number of passengers who use the service provided (people/month).

- GDP is the gross domestic product of Thailand (as 1998 constant price, million baht) has significantly negative relationship with the total number of passengers who use the service provided (people/month).

- GDP is the gross domestic product of Thailand (as 1998 constant price, million baht) has significantly positive relationship with the total number of passengers who use the service provided (people/month).

- EX is the exchange rate (Baht/Kip) has significantly positive relationship with the total number of passengers who use the service provided (people/month).

- $\mathrm{HO}$ is the number of holidays in each month consisting of weekends and special occasion holidays has significantly positive relationship with the total number of passengers who use the service provided (people/month).

- TR is the frequency of service obtained from the service schedule has significantly positive relationship with the total number of passengers who use the service provided (people/month).

Justification of the Model Estimation Methods: The model estimation methods undertaken have to be appropriate in order to propose the results as well as policy implications and recommendations are plausible. As a consequence, it is needed to conduct multi steps and estimation techniques by following to assure the accurate and reliable of the results of study.

- The Unit Root Test

- The Co-integration Test

- The Coefficient Test

- The Error Correction Mechanism (ECM) Test

Model Validity and Rational Testing: The estimated econometric model conducted in this study is high and acceptable validity because it had been tested prior to construct the appropriate model by using various model testing methods. These methods consist of the selection of variables that consistent with the passenger transportation demand theory. The form of model had been tested and chose as co- 
integration and ECM models after other different models consideration. Nevertheless, this research has been conducted under the context of the Thai-Laos passenger transportation demand. Therefore, it is necessary to develop the proxy variables used to estimate because of the limitation of the data collection.

\section{Results}

This section explains results of study based on the empirical results from the previous section.

Unit Root Test: It can be explained that for all independent variables, the stationary level of time series data used in the estimated model needed to be tested first via the Augmented Dickey Fuller (ADF) test. This technique is an appropriate method of checking the mean and variance of data. The first order stationary level or I $(0)$ have three different model testing formats:

- No intercept and no trend equation

- Only intercept equation

- Both intercept and trend equation

The comparison result between ADF t-Statistic and McKinnon critical value has to be considered to accept or reject the null hypothesis that each independent variable has no unit root or stationary. The empirical comparison result above found that the null hypothesis can be accepted and that the stationary of almost independent time series variable is the same level because of the ADF t-Statistic is lower than the McKinnon critical value at different level of significance of $0.01,0.05$ and 0.10 respectively. Nevertheless, there are some independent variables which rejected the null hypothesis but accepted the alternative hypothesis consisting of HO and TR. The alternative hypothesis showed that there are both intercept and trend variables in the estimated model at $99 \%$ of the significance level. The above mentioned independent variables had to be tested to make all independent variables at the same stationary level. The higher stationary level was tested by using the first different order estimation technique to obtain the most accurate and reliable empirical results possible. This procedure revealed that all independent variables are stationary at the same level of the first different order or I(1). The different levels of significance of $0.01,0.05$ and 0.10 are used to support this claim.

Co-integration Test: For the next step, the long-term relationship of the time series data was tested by using a co-integration process of the Engle and Granger test consisting of the following procedures: Firstly, the residuals of error term $\left(\varepsilon_{\mathrm{t}}\right)$ obtained from an estimated equation using OLS had to be taken to test the stationary level of the total number of customers who used the service (Qa) as well as other independent variables. The integration of zero order or unit root test by using ADF test was then calculated. The final step was to take the residual from the estimated equation by OLS to test the stationary level via the same process. Regarding the empirical results, it can be stated that the ADF test is less than the McKinnon critical value at a significant level of 0.01 . As a consequence, it can be concluded that the error term has the stationary characteristic or integration of order zero or I(0). Therefore, the total number of passengers who used the international transportation service between Thailand and Laos (Qa) has a long-term equilibrium relationship with each independent variable. However, the multicollinearity can be detected by considering the correlation coefficient of two independent variables of $\mathrm{Pa}$ and $\mathrm{Pb}$ that is equal to 0.9998 . Consequently, the independent variable of substitute good $(\mathrm{Pb})$ can be deleted from the estimated equation. Furthermore, the first conclusion that can be drawn is that the independent variables $\mathrm{Pa}$ and $\mathrm{Pb}$ are nearly perfect substitute goods, which is consistent with demand theory.

Coefficient Test: The next step after the co-integration process was coefficient testing in order to detect any heteroskedasticity and autocorrelation problems. Heteroskedasticity were tested by co-integration estimation results and autocorrelation problems were tested by using the Durbin-Watson (DW) statistic. The outcome was that no problems were detected. It can be implied that the total number of passengers (Q) has a long-term equilibrium relationship with all independent variables. This relationship can be written as follows:

$$
\begin{aligned}
& Q a=-140,450.3+903.5 P a+0.91 G D P-1,952.3 E X+3,126.5 H O+2,209.8 T R \\
& (1.73)^{*}(3.14)^{* * *}(-2.66)^{* *}(1.10) \quad(2.07)^{*} \\
& R^{2}=0.53 \quad \overline{R^{2}}=0.40 \\
& \text { S.E. }=17,551.96 \quad D . W .=2.30 \\
& F=0.011^{* *}
\end{aligned}
$$


Notes: $1 .^{* * *}$ is statistic level of significance at $1 \%(0.01)$

$2 .{ }^{* *}$ is statistic level of significance at $5 \%(0.05)$

$3 .{ }^{*}$ is statistic level of significance at $10 \%(0.10)$

The number in blanket is t-statistic: From the equation above, it can be explained that the total number of passengers from Thailand to Laos $(\mathrm{Qa})$ has a positive relationship with the fee (Pa), the frequency of service provided (TR) and the GDP. On the other hand, the total number of passengers from Thailand to Laos (Qa) has a negative relationship with the exchange rate (EX). Moreover, it can obvious seen that both with the fee $(\mathrm{Pa})$ has significantly positive relationship with the total number of passengers from Thailand to Laos (Qa). In addition, the exchange rate (EX) has significantly negative relationship with the total number of passengers from Thailand to Laos $(\mathrm{Qa})$. These results are inconsistent with the passenger transportation demand theory. It can be described that the fee $(\mathrm{Pa})$ is variable that consist of the seasonal effect and the service providers in the market contain only 2 companies. As a consequence, the market is considered as oligopoly market. Therefore, the price is set by the service providers and the customers are price takers. Additionally, the exchange rate (Baht/Kip) has very fluctuation changed during the estimation period as well as baht currency has been accepted to use for transaction expenditure in Laos instead of the US dollar.

Error Correction Mechanism (ECM) Test: The ECM is a mechanism that enables an examination of the short-term equilibrium adjustment process. Therefore, the error equilibrium adjustment term is the linkage between short-term and long-term adjustment mechanism. This mechanism and linkage can be expressed as the following equation.

$$
\begin{aligned}
& \Delta Q a_{t}=349.60+475.93 \Delta P a_{t}+0.40 \Delta G D P_{t}-642.88 \Delta E X_{t}+3580.23 \Delta H O_{t} \\
& +2480 \Delta T R_{t}-0.46 E C M_{t-1}
\end{aligned}
$$

A change of the total number of passengers using the transportation service between Thailand and Laos influences the change of fee (Pa), the frequency of service provided (TR) and the GDP in the same positive direction. However, a change in the total number of passengers influences the exchange rate (EX) and the number of holidays (HO) in the opposite direction. The negative coefficient of error correction term is consistent with the equilibrium adjustment theory. According to this theory, the value of error will be much lower leading to an adjustment for long-term equilibrium. It can be stated that the speed of adjustment to the long-term equilibrium is $-46.27 \%$ if there are situations that influence the total number of passengers that deviate from equilibrium in each period. The Breusch-Godfrey serial correlation LM test is used to test and accept the hypothesis that there no autocorrelation occurred at the $1 \%(0.01)$ significant level.

Discussion: Both the unit root test and co-integration processes are undertaken prior to the estimation by the OLS. It was found that the total number of passengers (Qa) has a long-term equilibrium relationship in the same direction with the fee (Pa), the frequency of service provided (TR) and the GDP. Nevertheless, the total number of passengers (Qa) has a long-term equilibrium relationship in the opposite direction with the exchange rate (EX). All of the independent variables can be used to explain the dependent variable of more than 53\%. Furthermore, the empirical results of the ECM supported the fact that the speed of adjustment when the total number of passengers deviates from the equilibrium to return to long-term equilibrium is approximately $46.3 \%$ in each time period. According to the empirical results, it can be concluded that the impact of determinant variables has different impact on passenger transportation demand. Both the relationship and size of effect can be observed from the coefficients. In addition, the impact of most variables is consistent with the passenger transportation demand theory except for the exchange rate. Thus, the results of different impact of determinant variables can be used to propose the policy implications and recommendations as well as the guideline to improve the service quality for passengers.

Policy Implications and Recommendations: According to the results of study, the policy implications and recommendations can be discussed and proposed as follows:

- Entrepreneurs should increase the frequency of service to meet the demand and provide more an efficient and convenient service which could promote tourism between the two countries.

- Both governments should encourage more entrepreneurs to participate in the industry to enhance competition.

- More competition will lead to increased service quality. 
- Entrepreneurs should use technology in order to improve efficiency e.g. an on-line ticketing system.

- Customs and immigration procedures at the check points of both countries should be reduced to save time for passengers.

It can be postulated that all policy implications and recommendations above are plausible. These policy implications and recommendations both need collective cooperation between the two countries. Additionally, these policy implications and recommendations are crucial schemes for trade and investment facilitation under the umbrella of the AEC implementation framework.

\section{Conclusion}

International passenger transportation is one of the essential industries that can enhance trade and investment between Thailand and Laos. The most important policy implications and recommendations are to improve the efficiency in terms of quality, frequency and use of technology e.g. on-line ticketing system. Another necessary policy recommendation is to develop the area to provide more passenger convenience and cleanliness. An improvement in the transportation efficiency is one possible way to facilitate trade and investment expansion not only for both countries but also for intra-ASEAN region. The success of the ASEAN Economic Community (AEC) depends on this support criterion.

Suggestion for Further Studies: This study can be extended to analyze and examine an appropriate passenger transportation model between Thailand and Laos. This model could also be used to measure the impact of the passenger transportation service on the economic growth of both countries. Moreover, this study can also be extended to forecast the growth of passenger numbers through estimation techniques and an appropriate model. Additionally, the elasticity of the passenger transportation demand model can be examined to analyze the optimum price. The optimum price will lead to increased market competition, efficiency and benefits for consumers. In addition, this study can also be extended to cover longer and update estimation period.

\section{References}

Hsu, C. \& Chao, C. C. (2005). Space Allocation for Commercial Activities at the International Passenger Terminal, Transportation Research, Part E, 29-51.

Matthews, L. (1995). Forecasting Peak Passenger Flows at Airport, Transportation, Kluwer Academic Publishers, the Netherlands, 55-72.

Poore, J. W. (1993). Forecasting the Demand for Air Transportation Services. Journal of Transportation Engineering, 15(5), 22-34.

Yamaguchi, K., Ueda, T., Ohashi, T., Takuma, F., Tsuchiya, K. \& Hikeda, T. (2001). Economic Impact Analysis of Deregulation and Airport Capacity Extension in Japanese Domestic Aviation Market. 